\title{
Increased peritoneal permeability at peritoneal dialysis initiation is a potential cardiovascular risk in patients using biocompatible peritoneal dialysis solution
}

Yoshifumi Hamasaki ${ }^{1}$, Kent Doi ${ }^{2}$, Mototsugu Tanaka ${ }^{3}$, Haruki Kume ${ }^{4}$, Yoshitaka Ishibashi $^{5}$, Yutaka Enomoto ${ }^{6}$, Toshiro Fujita ${ }^{7}$, Yukio Homma ${ }^{4}$, Masaomi Nangaku ${ }^{3}$ and Eisei Noiri ${ }^{3^{*}}$

\begin{abstract}
Background: Cardiovascular disease is a frequent cause of death in peritoneal dialysis patients. Biocompatible peritoneal dialysis solutions with neutral $\mathrm{pH}$ have been anticipated to reduce cardiovascular disease more than conventional peritoneal dialysis solutions with low pH, but it remains unclear which factors at peritoneal dialysis initiation increase cardiovascular risk in patients using biocompatible peritoneal dialysis solutions. This study was undertaken to investigate which clinical factors at peritoneal dialysis initiation, including peritoneal transport status, are associated with cardiovascular event in patients using biocompatible peritoneal dialysis solution.

Methods: This retrospective cohort study of peritoneal dialysis patients using biocompatible solutions with neutral $\mathrm{pH}$ assessed relations of clinical parameters at peritoneal dialysis initiation to cardiovascular event during the subsequent five years.

Results: Of 102 patients who started peritoneal dialysis, cardiovascular event occurred in 18. Age, history of cardiovascular disease before peritoneal dialysis initiation, hemoglobin, serum albumin, C-reactive protein, peritoneal permeability defined by the ratio of dialysate to plasma creatinine concentration at $4 \mathrm{hr}$ (D/Pcre) in peritoneal equilibration test (PET), number of patients in each PET category defined by D/Pcre, and peritoneal protein clearance significantly differed between patients with and without cardiovascular event. For patients divided according to PET category using Kaplan-Meier method, the group of high average to high peritoneal transporters exhibited significantly high incidence of cardiovascular event and mortality compared with the groups of low and low-average peritoneal transporters (Log rank; $p=0.0003$ and 0.005 , respectively). A Cox proportional hazards model showed independent association of PET category classification with cardiovascular event.
\end{abstract}

Conclusions: Peritoneal permeability expressed as PET category at peritoneal dialysis initiation is an independent cardiovascular risk factor in peritoneal dialysis patients using biocompatible peritoneal dialysis solution with neutral pH. Greater peritoneal permeability at peritoneal dialysis initiation might reflect subclinical vascular disorders.

Keywords: Biocompatible peritoneal dialysis solution, Cardiovascular disease, Peritoneal dialysis, Peritoneal equilibration test, Peritoneal permeability

\footnotetext{
* Correspondence: noiri-tky@umin.ac.jp

${ }^{3}$ Nephrology and Endocrinology, The University of Tokyo, 7-3-1 Hongo,

Bunkyo, Tokyo, Japan

Full list of author information is available at the end of the article
} 


\section{Background}

Cardiovascular disease (CVD) is the most common cause of death in end-stage renal disease (ESRD) patients. Cardiovascular mortality in ESRD patients is about 10-20 times higher than among the general population [1]. It is noteworthy that CVD causes not only high mortality but also disabilities, which make it difficult for patients to continue peritoneal dialysis (PD) therapy by themselves. Physical disability caused by CVD affects the selection of dialysis modality, which is one of the possible reasons for the lack of increase of PD patients [2]. Therefore, the management of CVD and its risk factors is a primary goal for PD patients [3]. Several non-traditional cardiovascular risk factors specific for PD therapy are known, such as decreased residual renal function, ultrafiltration failure, and peritoneal protein loss [3-5].

Although these findings were derived mainly from data of patients using conventional PD solutions (CPDSs) with low $\mathrm{pH}$, biocompatible PD solutions (BPDSs) with neutral $\mathrm{pH}$ have been widely used currently. Nevertheless, risk factors of CVD in PD patients using BPDSs remain unclear. This study investigated a patient cohort to clarify the association of clinical parameters at PD initiation, especially those specific for PD patients including peritoneal transport status, with cardiovascular event occurrence in patients using BPDS.

\section{Methods}

\section{Patients and data collection}

This retrospective cohort study used data of PD patients obtained from medical records at a single center: The University of Tokyo Hospital. The Institutional Review
Board of The University of Tokyo approved the study. Because this study retrospectively collected the data available from the medical records, the Institutional Review Board of The University of Tokyo waives the requirement to obtain documentation of the consent.

In actuality, 137 adult patients started PD therapy during 2001-2009. After excluding patients who had received maintenance hemodialysis or kidney transplantation before PD initiation and those who had been followed up for less than 6 months after PD initiation, 102 patients were analyzed in this study. All patients underwent PD using glucose-based BPDS with neutral $\mathrm{pH}$ and devices provided by Terumo Corp. (Tokyo, Japan). Within 6 months after PD initiation, peritoneal membrane function by peritoneal equilibration test (PET), urinary and peritoneal solute clearance, and peritoneal protein excretion were evaluated in all patients. In PET, $2.5 \%$ glucose concentration 2-L volume PD solution was used. The ratio of creatinine concentration in dialysate to plasma at the completion of the $4 \mathrm{~h}$ dwell period (D/Pcre) was evaluated to estimate lowmolecular-weight solute transport [6]. All the patients were classified into PET categories by the value of D/Pcre [6]. Then they were divided into three groups: low (L) transporters $(\mathrm{D} /$ Pcre $<0.50)$, low-average (LA) transporters $(0.50 \leq \mathrm{D} /$ Pcre $<0.65)$, and high-average to high $(\mathrm{HA}+\mathrm{H})$ transporters $(\mathrm{D} /$ Pcre $\geq 0.65)$. The body weight and blood pressure were measured on the same day of PET. Patient data at PD initiation were collected, including age, gender, cause of ESRD, and CVD history before PD initiation.

Laboratory data were measured at the time of PET. Residual renal function and dialysis dosage were calculated as the weekly Kt/V from the $24 \mathrm{~h}$ urinary and

Table 1 Patient characteristics at PD initiation $(N=102$, mean \pm SD)

\begin{tabular}{|c|c|c|c|}
\hline Age (years) & $60.6 \pm 13.9$ & Serum albumin $(\mathrm{g} / \mathrm{dl})$ & $3.5 \pm 0.5$ \\
\hline Male gender ( $n[\%])$ & 78 [77\%] & Blood urea nitrogen (mg/dl) & $52.1 \pm 14.7$ \\
\hline Cause of ESRD ( $n[\%])$ & & Serum creatinine $(\mathrm{mg} / \mathrm{dl})$ & $6.6 \pm 2.5$ \\
\hline Diabetes & 35 [34\%] & Serum corrected calcium (mg/dl) & $8.9 \pm 1.1$ \\
\hline Glomerulonephritis & 34 [33\%] & Serum phosphate $(\mathrm{mg} / \mathrm{dl})$ & $4.6 \pm 1.1$ \\
\hline Nephrosclerosis & 15 [15\%] & C-reactive protein (mg/dl) & $0.43 \pm 0.68$ \\
\hline Others & 18 [18\%] & Total cholesterol (mg/dl) & $198 \pm 39$ \\
\hline Diabetes mellitus ( $n[\%]$ ) & 35 [34\%] & Triglyceride (mg/dl) & $173 \pm 129$ \\
\hline CVD before PD initiation ( $n$ [\%]) & $25[25 \%]$ & Renal weekly Kt $/ \mathrm{N}$ & $1.14 \pm 0.62$ \\
\hline Automated PD ( $[\%])$ & 91 [89\%] & Total weekly Kt/N & $2.23 \pm 0.58$ \\
\hline Body mass index $\left(\mathrm{kg} / \mathrm{m}^{2}\right)$ & $22.1 \pm 3.4$ & D/Pcre & $0.59 \pm 0.12$ \\
\hline Systolic blood pressure $(\mathrm{mmHg})$ & $131 \pm 18$ & PET category & \\
\hline Diastolic blood pressure (mmHg) & $77 \pm 12$ & L & 19 [19\%] \\
\hline Urine volume (ml/day) & $1182 \pm 612$ & LA & $59[58 \%]$ \\
\hline UF volume (ml/day) & $446 \pm 658$ & $\mathrm{HA}+\mathrm{H}$ & 24 [24\%] \\
\hline Hemoglobin (g/dl) & $10.7 \pm 1.6$ & $\mathrm{P}-\mathrm{PrCl}$ (ml/day) & $58.9 \pm 26.9$ \\
\hline
\end{tabular}

ESRD, end stage renal disease; CVD, cardiovascular disease; UF, ultrafiltration; D/Pcre, the ratio of creatinine concentration in dialysate to plasma at the completion of the $4 \mathrm{~h}$ dwell period in peritoneal equilibration test; PET, peritoneal equilibration test; P-PrCl, peritoneal protein clearance. 
dialysate clearance by direct measurement of urea in urine and dialysate. To evaluate peritoneal protein excretion, peritoneal protein clearance $(\mathrm{P}-\mathrm{PrCl})$ was calculated as described previously [5,7]. Occurrence of cardiovascular event (CV event) after PD initiation was examined based on medical records and was evaluated as a primary outcome. CV event was defined for this study as follows: coronary artery disease which needs to be treated by angioplasty or coronary artery bypass,

Table 2 Comparison between patient groups with or without cardiovascular event within five years after PD initiation

\begin{tabular}{|c|c|c|c|}
\hline \multirow[t]{2}{*}{ Variables } & \multicolumn{2}{|c|}{$\begin{array}{l}\text { Cardiovascular event } \\
(\text { mean } \pm \text { SD) }\end{array}$} & \multirow[t]{2}{*}{$p$ value } \\
\hline & $(-) N=84$ & (+) $N=18$ & \\
\hline Age (years) & $59.1 \pm 14.3$ & $67.4 \pm 9.7$ & $<0.01$ \\
\hline Male gender & $75 \%$ & $83 \%$ & 0.45 \\
\hline Cause of ESRD & & & 0.67 \\
\hline Diabetes & $31 \%$ & $50 \%$ & \\
\hline Glomerulonephritis & $36 \%$ & $22 \%$ & \\
\hline Nephrosclerosis & $15 \%$ & $11 \%$ & \\
\hline Others & $18 \%$ & $17 \%$ & \\
\hline Diabetes mellitus & $31 \%$ & $50 \%$ & 0.13 \\
\hline CVD before PD initiation & $20 \%$ & $44 \%$ & 0.03 \\
\hline Automated PD & $88 \%$ & $94 \%$ & 0.43 \\
\hline Body mass index $\left(\mathrm{kg} / \mathrm{m}^{2}\right)$ & $22.1 \pm 3.4$ & $21.7 \pm 3.3$ & 0.73 \\
\hline Systolic blood pressure (mmHg) & $130 \pm 18$ & $140 \pm 18$ & 0.07 \\
\hline Diastolic blood pressure $(\mathrm{mmHg})$ & $77 \pm 12$ & $75 \pm 12$ & 0.24 \\
\hline Urine volume (ml/day) & $1166 \pm 579$ & $1258 \pm 763$ & 0.57 \\
\hline UF volume (ml/day) & $477 \pm 640$ & $286 \pm 745$ & 0.31 \\
\hline Hemoglobin (g/dl) & $10.8 \pm 1.7$ & $10.2 \pm 1.1$ & 0.03 \\
\hline Serum albumin (g/dl) & $3.6 \pm 0.5$ & $3.3 \pm 0.5$ & 0.01 \\
\hline Blood urea nitrogen $(\mathrm{mg} / \mathrm{dl})$ & $52.5 \pm 14.1$ & $50.1 \pm 17.2$ & 0.49 \\
\hline Serum creatinine (mg/dl) & $7.0 \pm 2.6$ & $5.7 \pm 2.3$ & 0.08 \\
\hline Serum corrected calcium (mg/dl) & $8.9 \pm 1.2$ & $9.0 \pm 0.7$ & 0.90 \\
\hline Serum phosphate (mg/dl) & $4.7 \pm 1.1$ & $4.3 \pm 1.3$ & 0.10 \\
\hline C-reactive protein (mg/dl) & $0.39 \pm 0.65$ & $0.63 \pm 0.83$ & 0.05 \\
\hline Total cholesterol (mg/dl) & $198 \pm 40$ & $201 \pm 38$ & 0.87 \\
\hline Triglyceride (mg/dl) & $175 \pm 138$ & $164 \pm 74$ & 0.49 \\
\hline Renal weekly Kt/N & $1.16 \pm 0.65$ & $1.12 \pm 0.52$ & 0.99 \\
\hline Total weekly Kt/N & $2.23 \pm 0.60$ & $2.19 \pm 0.50$ & 0.88 \\
\hline D/Pcre & $0.58 \pm 0.12$ & $0.65 \pm 0.11$ & $<0.01$ \\
\hline PET category & & & $<0.01$ \\
\hline L & $23 \%$ & $0 \%$ & \\
\hline LA & $60 \%$ & $50 \%$ & \\
\hline $\mathrm{HA}+\mathrm{H}$ & $18 \%$ & $50 \%$ & \\
\hline P-PrCl (ml/day) & $54.7 \pm 24.2$ & $72.7 \pm 34.1$ & 0.03 \\
\hline
\end{tabular}

cerebrovascular disease such as transient ischemic attack and stroke, and peripheral artery disease that requires surgical revascularization or amputation, which occurred within five years after PD initiation. Technique survival within five years after PD initiation and death from PD initiation to the first 1 year after PD cessation were also examined.

\section{Statistical analysis}

Continuous and categorical data were expressed respectively as means $\pm \mathrm{SD}$ and proportions. Data were compared

Table 3 Comparison between patient groups with or without death after PD initiation

\begin{tabular}{|c|c|c|c|}
\hline \multirow[t]{2}{*}{ Variables } & \multicolumn{2}{|c|}{ Death (mean \pm SD) } & \multirow[t]{2}{*}{$p$ value } \\
\hline & $(-) N=87$ & $(+) N=15$ & \\
\hline Age (years) & $58.0 \pm 12.8$ & $75.3 \pm 11.0$ & $<0.01$ \\
\hline Male gender & $78 \%$ & $67 \%$ & 0.33 \\
\hline Cause of ESRD & & & 0.05 \\
\hline Diabetes & $33 \%$ & $40 \%$ & \\
\hline Glomerulonephritis & $39 \%$ & $0 \%$ & \\
\hline Nephrosclerosis & $11 \%$ & $33 \%$ & \\
\hline Others & $16 \%$ & $27 \%$ & \\
\hline Diabetes mellitus & $34 \%$ & $40 \%$ & 0.62 \\
\hline CVD before PD initiation & $24 \%$ & $27 \%$ & 0.85 \\
\hline Automated PD & $91 \%$ & $80 \%$ & 0.22 \\
\hline Body mass index $\left(\mathrm{kg} / \mathrm{m}^{2}\right)$ & $22.2 \pm 3.3$ & $21.3 \pm 3.8$ & 0.36 \\
\hline Systolic blood pressure $(\mathrm{mmHg})$ & $130 \pm 17$ & $134 \pm 24$ & 0.48 \\
\hline Diastolic blood pressure (mmHg) & $78 \pm 11$ & $67 \pm 14$ & $<0.01$ \\
\hline Urine volume (ml/day) & $1222 \pm 619$ & $948 \pm 530$ & 0.11 \\
\hline UF volume (ml/day) & $484 \pm 649$ & $249 \pm 693$ & 0.21 \\
\hline Hemoglobin (g/dl) & $10.8 \pm 1.7$ & $10.2 \pm 1.2$ & 0.04 \\
\hline Serum albumin (g/dl) & $3.6 \pm 0.4$ & $3.1 \pm 0.5$ & $<0.01$ \\
\hline Blood urea nitrogen (mg/dl) & $53.0 \pm 14.4$ & $46.6 \pm 15.4$ & 0.11 \\
\hline Serum creatinine (mg/dl) & $6.9 \pm 2.5$ & $4.5 \pm 1.9$ & $<0.01$ \\
\hline Serum corrected calcium (mg/dl) & $8.9 \pm 1.2$ & $9.1 \pm 0.7$ & 0.55 \\
\hline Serum phosphate (mg/dl) & $4.8 \pm 1.1$ & $3.9 \pm 0.8$ & $<0.01$ \\
\hline C-reactive protein (mg/dl) & $0.40 \pm 0.69$ & $0.61 \pm 0.60$ & $<0.01$ \\
\hline Total cholesterol (mg/dl) & $199 \pm 39$ & $193 \pm 41$ & 0.58 \\
\hline Triglyceride (mg/dl) & $178 \pm 136$ & $147 \pm 73$ & 0.86 \\
\hline Renal weekly Kt/N & $1.13 \pm 0.63$ & $1.23 \pm 0.58$ & 0.57 \\
\hline Total weekly Kt/N & $2.21 \pm 0.56$ & $2.30 \pm 0.73$ & 0.61 \\
\hline D/Pcre & $0.58 \pm 0.11$ & $0.67 \pm 0.15$ & 0.03 \\
\hline PET category & & & $<0.01$ \\
\hline L & $21 \%$ & $7 \%$ & \\
\hline LA & $61 \%$ & $40 \%$ & \\
\hline $\mathrm{HA}+\mathrm{H}$ & $18 \%$ & $53 \%$ & \\
\hline P-PrCl (ml/day) & $56.3 \pm 27.9$ & $67.5 \pm 17.3$ & 0.02 \\
\hline
\end{tabular}


using Mann-Whitney u-test, chi-square test, and Cochran-Armitage test. Incidence of CV event, mortality, and technique survival rate were examined by comparing patients divided into PET categories using the Kaplan-Meier method and the log-rank test. Predictors of $\mathrm{CV}$ event were identified using the Cox proportional hazards model with variables that were significantly different between groups with and without $\mathrm{CV}$ event with a $p$ value of less than or equal to 0.01 . A $p$ value of less than 0.05 was inferred as statistically significant.

Statistical analyses were conducted using software (JMP 9.0; SAS Institute Inc., Cary, NC).

\section{Results}

\section{Patient data and characteristics}

Table 1 presents patient data and characteristics at PD initiation. All 102 patients were treated with glucose- based PD solutions with neutral pH (MIDPERIQ L ${ }^{\circledR} 135$ or MIDPERIQ L ${ }^{\bullet} 250$; Terumo Corp.). For this study, patients were classified into groups: 19 (19\%) into the L group, 59 (58\%) into the LA group, and 24 (24\%) into the $\mathrm{HA}+\mathrm{H}$ group (HA group, $\mathrm{n}=18 ; \mathrm{H}$ group, $\mathrm{n}=6$ ) (Table 1). Of the 102 patients, 91 (89\%) were treated continuously by automated PD (APD) from immediately after PD initiation to cessation of PD. In these patients, APD instead of continuous ambulatory PD (CAPD) was selected according to patient preferences. Laboratory data collection was performed more than 1 month after PD catheter insertion to avoid the influence of surgery. The recommended period to perform first PET after PD initiation is within 3 months [8]. In this study, the mean ( \pm standard deviation) duration from PD initiation to laboratory data collection was $2.9 \pm 1.6$ months.
A

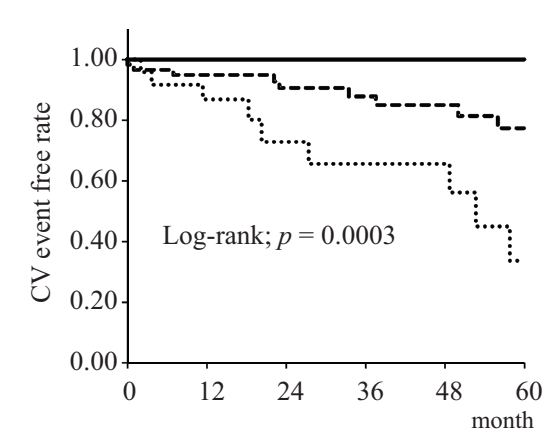

B

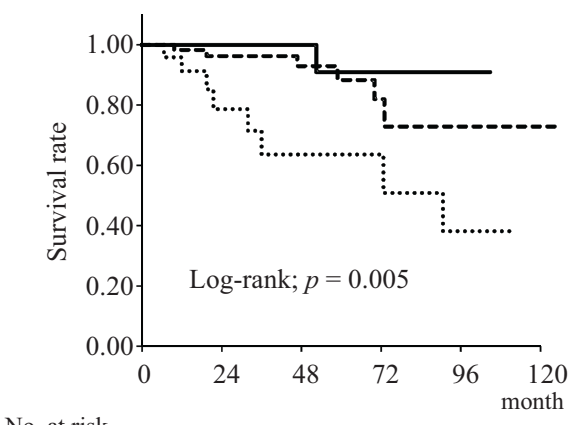

C

$\begin{array}{lrrrrrr}\mathrm{L} & 19 & 19 & 17 & 15 & 11 & 9 \\ \mathrm{LA} & 59 & 54 & 42 & 31 & 26 & 16 \\ \mathrm{HA}+\mathrm{H} & 24 & 18 & 10 & 7 & 6 & 3\end{array}$

$\begin{array}{lrrrrr}\text { No. at risk } & & & & & \\ \text { L } & 19 & 19 & 11 & 8 & 1 \\ \text { LA } & 59 & 56 & 28 & 11 & 4 \\ \text { HA }+ \text { H } & 24 & 20 & 8 & 5 & 3\end{array}$

Technique survival
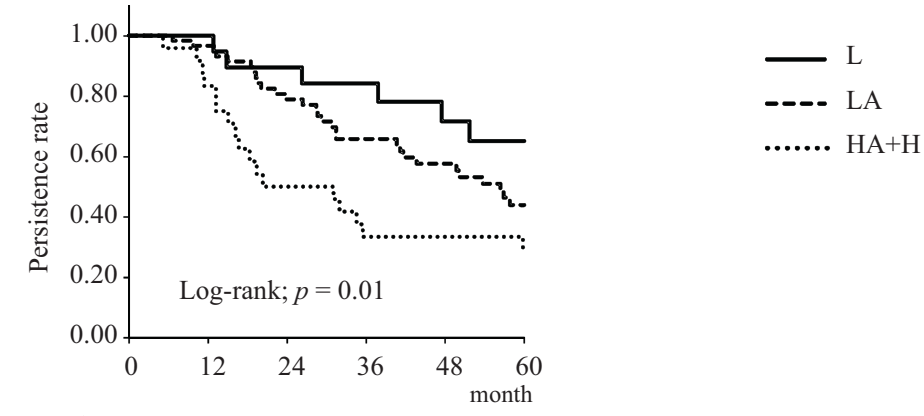

$\begin{array}{lllrrrr}\text { No. at risk } & & & & & & \\ \text { L } & 19 & 19 & 17 & 15 & 11 & 9 \\ \text { LA } & 59 & 56 & 44 & 33 & 28 & 18 \\ \text { HA+H } & 24 & 20 & 12 & 8 & 8 & 6\end{array}$

Figure 1 Kaplan-Meier plots of incidence of CV event (A), survival rate (B), and technique survival rate (C) of PD patients using BPDS with neutral pH according to PET category. 102 patients were divided into three groups based on PET category defined by D/Pcre. Patients with $\mathrm{D} / \mathrm{Pcre}<0.50$ are in the low $(\mathrm{L})$ group $(n=19), 0.50 \leq \mathrm{D} / \mathrm{Pcre}<0.65$ are in the low average $(\mathrm{LA})$ group $(n=59)$, and D/Pcre $\geq 0.65$ are in the high average and high $(H A+H)$ group $(n=24)$. 


\section{Occurrence of $\mathrm{CV}$ event and death after PD initiation}

A CV event occurred in 18 patients (17.6\%) within five years after PD initiation. Table 2 presents variables for which a significant difference was found between groups with and without a CV event. Age, prevalence of CVD before PD initiation, C-reactive protein, D/Pcre, and $\mathrm{P}-\mathrm{PrCl}$ were significantly higher, and hemoglobin and serum albumin were significantly lower in the group of patients with $\mathrm{CV}$ event than in the group of patients without CV event (Table 2). Distributions of patients classified into each PET category differed significantly between groups with and without CV event (Table 2).

Of 102 patients, 15 patients (15\%) were confirmed to have died between PD initiation and 1 year after PD cessation. Distributions of patients classified into each PET category differed significantly between the groups with and without death (Table 3).

\section{Impact of PET category classification at PD initiation on the prognosis of PD patients}

The incidence of $\mathrm{CV}$ event, survival rate, and technique survival rate were examined by comparing patients in the L, LA, and HA + H groups using the Kaplan-Meier method and the log-rank test (Figure 1). Patients in the $\mathrm{HA}+\mathrm{H}$ group had worse CVD morbidity, survival rate, and technique survival rate than those in the L or LA group. Patients in the $\mathrm{HA}+\mathrm{H}$ group had significantly lower levels of serum albumin and higher $\mathrm{P}-\mathrm{PrCl}$ than those in the L or LA group (Table 4).

Table 4 Comparison between groups divided according to PET category defined by D/Pcre

\begin{tabular}{|c|c|c|c|c|}
\hline \multirow[t]{3}{*}{ Variables } & \multicolumn{3}{|c|}{ PET category (mean \pm SD) } & \multirow[t]{3}{*}{$p$ value } \\
\hline & $\mathbf{L}$ & LA & $\mathrm{HA}+\mathrm{H}$ & \\
\hline & $N=19$ & $N=59$ & $N=24$ & \\
\hline Age (years) & $60.4 \pm 15.5$ & $58.9 \pm 13.7$ & $64.9 \pm 13.0$ & 0.24 \\
\hline Male gender & $68 \%$ & $78 \%$ & $79 \%$ & 0.66 \\
\hline Cause of ESRD & & & & 0.74 \\
\hline Diabetes & $26 \%$ & $32 \%$ & $46 \%$ & \\
\hline Glomerulonephritis & $52 \%$ & $32 \%$ & $21 \%$ & \\
\hline Nephrosclerosis & $11 \%$ & $15 \%$ & $17 \%$ & \\
\hline Others & $11 \%$ & $20 \%$ & $17 \%$ & \\
\hline Diabetes mellitus & $26 \%$ & $32 \%$ & $46 \%$ & 0.54 \\
\hline CVD before PD initiation & $16 \%$ & $24 \%$ & $33 \%$ & 0.62 \\
\hline Automated PD & $90 \%$ & $88 \%$ & $92 \%$ & 0.99 \\
\hline Body mass index $\left(\mathrm{kg} / \mathrm{m}^{2}\right)$ & $20.9 \pm 2.8$ & $22.6 \pm 3.5$ & $21.8 \pm 3.5$ & 0.18 \\
\hline Systolic blood pressure $(\mathrm{mmHg})$ & $126 \pm 14$ & $132 \pm 18$ & $134 \pm 22$ & 0.31 \\
\hline Diastolic blood pressure $(\mathrm{mmHg})$ & $75 \pm 12$ & $78 \pm 11$ & $75 \pm 15$ & 0.54 \\
\hline Urine volume (ml/day) & $1155 \pm 401$ & $1260 \pm 684$ & $1012 \pm 543$ & 0.49 \\
\hline UF volume (ml/day) & $654 \pm 440$ & $437 \pm 616$ & $300 \pm 868$ & 0.24 \\
\hline Hemoglobin (g/dl) & $11.2 \pm 1.2$ & $10.6 \pm 1.9$ & $10.6 \pm 1.2$ & 0.28 \\
\hline Serum albumin ( $g / d l)$ & $3.8 \pm 0.4$ & $3.6 \pm 0.4$ & $3.3 \pm 0.5^{* * * *}$ & $<0.01$ \\
\hline Blood urea nitrogen (mg/dl) & $50.8 \pm 15.8$ & $54.2 \pm 13.8$ & $47.9 \pm 15.3$ & 0.26 \\
\hline Serum creatinine (mg/dl) & $6.5 \pm 2.0$ & $6.9 \pm 2.6$ & $5.9 \pm 2.7$ & 0.28 \\
\hline Serum corrected calcium (mg/dl) & $9.1 \pm 0.8$ & $8.8 \pm 1.3$ & $9.0 \pm 0.7$ & 0.66 \\
\hline Serum phosphate (mg/dl) & $4.7 \pm 1.4$ & $4.9 \pm 1.0$ & $4.1 \pm 1.0^{* *}$ & $<0.01$ \\
\hline C-reactive protein (mg/dl) & $0.38 \pm 0.83$ & $0.41 \pm 0.62$ & $0.54 \pm 0.73$ & 0.09 \\
\hline Total cholesterol (mg/dl) & $197 \pm 27$ & $195 \pm 44$ & $207 \pm 37$ & 0.35 \\
\hline Triglyceride (mg/dl) & $227 \pm 215$ & $161 \pm 105$ & $160 \pm 69$ & 0.39 \\
\hline Renal weekly Kt/N & $1.26 \pm 0.56$ & $1.14 \pm 0.60$ & $1.09 \pm 0.74$ & 0.58 \\
\hline Total weekly Kt/N & $2.21 \pm 0.53$ & $2.20 \pm 0.54$ & $2.32 \pm 0.73$ & 0.95 \\
\hline D/Pcre & $0.45 \pm 0.05$ & $0.57 \pm 0.05^{*}$ & $0.75 \pm 0.10^{* * * *}$ & $<0.01$ \\
\hline P-PrCl (ml/day) & $44.2 \pm 23.4$ & $56.0 \pm 24.9$ & $74.1 \pm 27.8^{* * * *}$ & $<0.01$ \\
\hline
\end{tabular}

${ }^{*} p<0.05$ vs. L group; ${ }^{* *} p<0.05$ vs. LA group. 
Results of the Cox proportional hazards model on $\mathrm{CV}$ event in five years after PD initiation are shown (Table 5). Regarding forward stepwise multivariate analysis, the PET category remained as an independent predictor of CV event (Table 5). When analysis using the Cox proportional hazards model was conducted using variables that were significantly different between the patient groups with and without $\mathrm{CV}$ event with $p$ value of less than or equal to 0.05 , the PET category was determined as an independent predictor of CV event (Table 5).

\section{Discussion}

This study demonstrated that peritoneal small solute permeability, expressed as PET category classification defined by $\mathrm{D} /$ Pcre, was independently associated with a $\mathrm{CV}$ event within five years after PD initiation in patients using BPDS. This report is the first describing evaluation of the relation between clinical parameters at PD initiation and prognosis in patients using BPDS with neutral $\mathrm{pH}$, although many previous clinical studies evaluated this relation in patients using CPDSs and icodextrin with low $\mathrm{pH}$.

Our results showed that PET category at PD initiation is an independent risk factor of CVD in PD patients using BPDF with neutral pH. Similar relations between peritoneal permeability and prognosis shown by our study have been demonstrated in previous studies in patients using CPDSs with low $\mathrm{pH}$ [9-11]. Because PD solutions have adverse effects on both the local peritoneal and systemic effects induced by glucose degradation products coupled with other factors such as low $\mathrm{pH}$, BPDSs had been anticipated for use to improve the prognosis of PD patients [12]. However, a recent systematic review was unable to demonstrate significant effects of BPDSs on survival and technique failure [13]. Results obtained from the present study support the view that the type of PD solution does not have a significant effect on the PD patient prognosis. Although the effects of BPDSs on prognosis remain unclear, some benefits have been reported. For instance, BPDSs have benefits of reducing peritoneal membrane injury, which might be favorable for the preservation of peritoneal ultrafiltration capacity and which might decrease the risk of CVD caused by fluid overload [14]. Reportedly, BPDSs can preserve residual renal function and levels of markers of endothelial dysfunction [13,15-17]. Because local and systemic effects of BPDSs are preferred to those of CPDSs, the fluid overload state, which plays a pivotal role in CVD progression, is expected to be improved by BPDSs [3,12]. The impact of BPDSs and clinical factors affecting the prognosis of patients using BPDSs should be investigated further.

Some possible explanations about the linkage between peritoneal permeability and prognosis of PD patients have been considered. High peritoneal permeability, which causes rapid equilibration of glucose across the peritoneal membrane, engenders ultrafiltration failure. A continuous fluid overload state accelerates left ventricular hypertrophy and increases serum concentrations of natriuretic peptides, which are markers of CVD and all-cause mortality in PD patients [3]. High peritoneal transport increases CVD morbidity and mortality by accelerating hypoalbuminemia, a well-known prognostic marker in PD patients, through increased peritoneal protein loss $[9,10]$. Increased peritoneal permeability is probably associated with high mortality in patients with malnutrition-inflammation-atherosclerosis (MIA) syndrome through peritoneal protein loss and hypoalbuminemia [18]. High transport status of the peritoneum might be a marker

Table 5 Univariate and multivariate Cox regression model on cardiovascular event within five years after PD initiation

\begin{tabular}{|c|c|c|c|c|c|}
\hline & \multirow[b]{2}{*}{ Variable } & \multicolumn{2}{|c|}{ Unadjusted } & \multicolumn{2}{|c|}{ Adjusted } \\
\hline & & Hazard ratio $[95 \% \mathrm{Cl}]$ & $p$ value & Hazard ratio $[95 \% \mathrm{Cl}]$ & $p$ value \\
\hline \multirow[t]{2}{*}{ Model 1} & Age & $1.03[0.99-1.06]$ & 0.09 & $1.03[0.99-1.06]$ & 0.09 \\
\hline & PET category & $3.70[1.62-8.43]$ & $<0.01$ & $3.70[1.62-8.43]$ & $<0.01$ \\
\hline \multirow[t]{3}{*}{ Model 2} & Age & $1.01[0.98-.1 .05]$ & 0.40 & - & - \\
\hline & Serum albumin & $0.29[0.08-1.02]$ & 0.05 & $0.24[0.08-0.77]$ & 0.02 \\
\hline & PET category & 3.21 [1.37-7.52] & $<0.01$ & 3.49 [1.49-8.15] & $<0.01$ \\
\hline \multirow[t]{7}{*}{ Model 3} & Age & $1.03[0.99-1.08]$ & 0.13 & 1.03 [0.99-1.07] & 0.11 \\
\hline & CVD before PD initiation & $1.82[0.58-5.69]$ & 0.31 & - & - \\
\hline & Hemoglobin & $0.91[0.66-1.26]$ & 0.57 & - & - \\
\hline & Serum albumin & 0.40 [0.09-1.83] & 0.24 & $0.31[0.09-1.11]$ & 0.07 \\
\hline & C-reactive protein & $1.19[0.55-2.61]$ & 0.65 & - & - \\
\hline & PET category & $4.65[1.78-12.16]$ & $<0.01$ & $4.25[1.79-10.10]$ & $<0.01$ \\
\hline & $\mathrm{P}-\mathrm{PrCl}$ & $0.99[0.97-1.01]$ & 0.54 & - & - \\
\hline
\end{tabular}


of preexisting vascular pathology associated with atherosclerotic comorbidity after PD initiation [19].

Several studies have revealed that high peritoneal permeability is not an independent risk factor of death and technique failure. In addition, high transporter treated by APD had superior survival and technique survival [20-22]. Actually, APD tends to be selected for patients with increased peritoneal permeability because short exchange of PD solution by automated cycler can increase ultrafiltration via reduction of glucose absorption [22]. In our study, almost all patients were treated by APD from immediately after PD initiation to cessation of PD whether their peritoneal permeability was increased or not. Therefore, the PET category at PD initiation might predict the prognoses of patients treated by APD.

Although classification into 'Slow' (D/Pcre $<0.55-$ $0.60)$, 'Average', and 'Fast' (D/Pcre $>0.80$ ) transporter status was recently recommended for prescription management in clinical practice [23], classification into the four PET categories (L, LA, HA, and H) has been used in many studies, as it was for this study. We divided the patients into the three categories of L, LA, and HA $+\mathrm{H}$ in this study. However one previous study, in which the HA group comprised most of the patients, showed no difference of $\mathrm{CV}$ event rate among the PET category groups of $\mathrm{L}+\mathrm{LA}, \mathrm{HA}$, and $\mathrm{H}$ [22]. When the patients in this study were divided into L + LA, HA, and H groups, or Slow, Average, and Fast groups, the Kaplan-Meier method and the log-rank test showed that the patients in the L + LA group or the Slow group of this study had a significantly high $\mathrm{CV}$ event free rate, patient survival rate, and technique survival rate (Additional file 1: Figures S1 and S2). Therefore, the association of peritoneal transport status with prognosis of PD patients using BPDS was apparently similar, irrespective of the patient categorization based on the PET results.

Our study has some limitations. This study was a retrospective cohort study of patients from a single center and the number of patients was not large. A large prospective study including patients using BPDS from multiple centers should be conducted. Because only glucose-based BPDS was used and because APD was mainly performed in this study, it remains unclear whether all the results from our study are applicable to patients using other PD solutions or treated by CAPD.

\section{Conclusions}

Peritoneal permeability expressed as PET category defined by $\mathrm{D} /$ Pcre at PD initiation is an independent cardiovascular risk factor in patients using BPDS. Increased peritoneal permeability at PD initiation might contribute to the progress of atherosclerosis in PD patients by several mechanisms such as fluid overload and MIA syndrome. Findings from this study can contribute to management of PD patients using BPDS by enabling identification of patients with high risk of CVD and by enabling early intervention to improve their prognosis from immediately after PD initiation.

\section{Additional file}

\begin{abstract}
Additional file 1: Kaplan-Meier plots of incidence of CV event (Figures S1A and S2A), survival rate (Figures S1B and S2B), and technique survival rate (Figures S1C and S2C) of PD patients according to PET category. 102 patients were divided into three groups based on PET category defined by D/Pcre. Patients with D/Pcre $<0.65$ are in the low and low-average $(L+L A)$ group $(n=78), 0.65 \leq \mathrm{D}$ / Pcre $\leq 0.80$ are in the high-average $(H A)$ group $(n=18)$, and D/Pcre $>0.80$ are in the high $(H)$ group $(n=6)$ (Figure S1). Patients with D/Pcre $<0.57$ are in the Slow group $(n=48), 0.57 \leq \mathrm{D} /$ Pcre $\leq 0.80$ are in the Average group $(n=48)$, and D/Pcre $>0.80$ are in the Fast group $(n=6)$ (Figure S2).
\end{abstract}

\section{Competing interests}

The authors declare that they have no competing interests.

\section{Authors' contributions}

$\mathrm{YH}, \mathrm{KD}$, and MT conceived of the study, participated in the design of the study, and performed statistical analyses. $\mathrm{YH}$ and $\mathrm{KD}$ drafted the manuscript. $H K, Y I, Y E, T F, Y H s, M N$, and EN participated in the design of the study and its coordination, and helped to draft the manuscript. All authors read and approved the final manuscript.

\section{Acknowledgments}

Grant and sources of support: KAKEN-HI \# 23790931, MEXT, Japan (KD); KAKEN-HI \# 24390212, MEXT, Japan (EN); KAKEN-HI \# 25860288, MEXT, Japan (YH).

Division of Total Renal Care Medicine in 22nd Century Medical and Research Center, to which the first author is belonged, is an endowment department supported with an unrestricted grant from Terumo Corp. (Tokyo, Japan).

\section{Author details}

${ }^{1}$ 22nd Century Medical and Research Center, The University of Tokyo Hospital, 7-3-1 Hongo, Bunkyo, Tokyo, Japan. ²Emergency and Critical Care Medicine, The University of Tokyo Hospital, Tokyo, Japan. ${ }^{3}$ Nephrology and Endocrinology, The University of Tokyo, 7-3-1 Hongo, Bunkyo, Tokyo, Japan. ${ }^{4}$ Urology, The University of Tokyo Hospital, Tokyo, Japan. ${ }^{5}$ Japanese Red Cross Medical Center, Tokyo, Japan. ${ }^{6}$ Mitsui Memorial Hospital, Tokyo, Japan. ${ }^{7}$ Division of Clinical Epigenetics, Research Center for Advanced Science and Technology (RCAST), The University of Tokyo, Tokyo, Japan.

Received: 17 July 2014 Accepted: 24 October 2014

Published: 1 November 2014

\section{References}

1. de Jager DJ, Grootendorst DC, Jager KJ, van Dijk PC, Tomas LM, Ansell D, Collart F, Finne P, Heaf JG, De Meester J, Wetzels JF, Rosendaal FR, Dekker FW: Cardiovascular and noncardiovascular mortality among patients starting dialysis. JAMA 2009, 302(16):1782-1789.

2. Lameire N, Van Biesen W: Epidemiology of peritoneal dialysis: a story of believers and nonbelievers. Nat Rev Nephrol 2010, 6(2):75-82.

3. Krediet RT, Balafa O: Cardiovascular risk in the peritoneal dialysis patient. Nat Rev Nephrol 2010, 6(8):451-460.

4. Perez-Fontan M, Rodriguez-Carmona A, Barreda D, Lopez-Muniz A, Blanco-Castro $\mathrm{N}$, Garcia-Falcon T: Peritoneal protein transport during the baseline peritoneal equilibration test is an accurate predictor of the outcome of peritoneal dialysis patients. Nephron Clin Pract 2010, 116(2):c104-c113.

5. Perl J, Huckvale K, Chellar M, John B, Davies SJ: Peritoneal protein clearance and not peritoneal membrane transport status predicts survival in a contemporary cohort of peritoneal dialysis patients. Clin J Am Soc Nephrol 2009, 4(7):1201-1206.

6. Twardowski ZJ, Nolph KD, Khanna R, Prowant BF, Ryan LP, Moore HL, Nielsen MP: Peritoneal equilibration test. Periton Dialys B 1987, 7(3):138-147. 
7. Elsurer R, Afsar B, Sezer S, Ozdemir FN, Haberal M: Peritoneal albumin leakage: 2 year prospective cardiovascular event occurrence and patient survival analysis. Nephrology (Carlton) 2009, 14(8):712-715.

8. National Kidney Foundation: Clinical practice recommendations for peritoneal dialysis adequacy. Am J Kidney Dis 2006, 48 Suppl 1:S130-S158.

9. Churchill DN, Thorpe KE, Nolph KD, Keshaviah PR, Oreopoulos DG, Page D: Increased peritoneal membrane transport is associated with decreased patient and technique survival for continuous peritoneal dialysis patients. The Canada-USA (CANUSA) Peritoneal Dialysis Study Group. J Am Soc Nephrol 1998, 9(7):1285-1292.

10. Rumpsfeld M, McDonald SP, Johnson DW: Higher peritoneal transport status is associated with higher mortality and technique failure in the Australian and New Zealand peritoneal dialysis patient populations. J Am Soc Nephrol 2006, 17(1):271-278.

11. Brimble KS, Walker M, Margetts PJ, Kundhal KK, Rabbat CG: Meta-analysis: peritoneal membrane transport, mortality, and technique failure in peritoneal dialysis. J Am Soc Nephrol 2006, 17(9):2591-2598.

12. Garcia-Lopez E, Lindholm B, Davies S: An update on peritoneal dialysis solutions. Nat Rev Nephrol 2012, 8(4):224-233.

13. Cho Y, Johnson DW, Badve SV, Craig JC, Strippoli GF, Wiggins KJ: The impact of neutral-pH peritoneal dialysates with reduced glucose degradation products on clinical outcomes in peritoneal dialysis patients. Kidney Int 2013, 84(5):969-979

14. Cho Y, Badve SV, Hawley CM, Wiggins K, Johnson DW: Biocompatible peritoneal dialysis fluids: clinical outcomes. Int J Nephrol 2012, 2012:812609.

15. Haag-Weber M, Kramer R, Haake R, Islam MS, Prischl F, Haug U, Nabut JL, Deppisch R: Low-GDP fluid (Gambrosol trio) attenuates decline of residual renal function in PD patients: a prospective randomized study. Nephrol Dial Transplant 2010, 25(7):2288-2296.

16. Williams JD, Topley N, Craig KJ, Mackenzie RK, Pischetsrieder M, Lage C, Passlick-Deetjen J: The Euro-Balance Trial: the effect of a new biocompatible peritoneal dialysis fluid (balance) on the peritoneal membrane. Kidney Int 2004, 66(1):408-418.

17. Park SH, Do JY, Kim YH, Lee HY, Kim BS, Shin SK, Kim HC, Chang YK, Yang JO, Chung HC, Kim CD, Lee WK, Kim JY, Kim YL: Effects of neutral pH and low-glucose degradation product-containing peritoneal dialysis fluid on systemic markers of inflammation and endothelial dysfunction: a randomized controlled 1-year follow-up study. Nephrol Dial Transplant 2012, 27(3):1191-1199.

18. Margetts PJ, McMullin JP, Rabbat CG, Churchill DN: Peritoneal membrane transport and hypoalbuminemia: cause or effect? Perit Dial Int 2000, 20(1):14-18.

19. Heaf JG, Sarac S, Afzal S: A high peritoneal large pore fluid flux causes hypoalbuminaemia and is a risk factor for death in peritoneal dialysis patients. Nephrol Dial Transplant 2005, 20(10):2194-2201.

20. Wiggins KJ, McDonald SP, Brown FG, Rosman JB, Johnson DW: High membrane transport status on peritoneal dialysis is not associated with reduced survival following transfer to haemodialysis. Nephrol Dial Transplant 2007, 22(10):3005-3012.

21. Johnson DW, Hawley CM, McDonald SP, Brown FG, Rosman JB, Wiggins KJ Bannister KM, Badve SV: Superior survival of high transporters treated with automated versus continuous ambulatory peritoneal dialysis. Nephrol Dial Transplant 2010, 25(6):1973-1979.

22. Yang X, Fang W, Bargman JM, Oreopoulos DG: High peritoneal permeability is not associated with higher mortality or technique failure in patients on automated peritoneal dialysis. Perit Dial Int 2008, 28(1):82-92.

23. van Biesen W, Heimburger O, Krediet R, Rippe B, La Milia V, Covic A, Vanholder R: Evaluation of peritoneal membrane characteristics: clinical advice for prescription management by the ERBP working group. Nephrol Dial Transplant 2010, 25(7):2052-2062.

doi:10.1186/1471-2369-15-173

Cite this article as: Hamasaki et al.: Increased peritoneal permeability at peritoneal dialysis initiation is a potential cardiovascular risk in patients using biocompatible peritoneal dialysis solution. BMC Nephrology 2014 15:173.

\section{Submit your next manuscript to BioMed Central and take full advantage of:}

- Convenient online submission

- Thorough peer review

- No space constraints or color figure charges

- Immediate publication on acceptance

- Inclusion in PubMed, CAS, Scopus and Google Scholar

- Research which is freely available for redistribution

Submit your manuscript at www.biomedcentral.com/submit
() Biomed Central 